\section{Aversion to xenotransplantation}

SIR - A recent news item in Nature reported that experts regard xenotransplantation as a new medical field with explosive growth potential. They foresee a
Opposition to xenotransplantation is not limited to acute care nurses, but is also expressed by others, including animal rights activists, actual transplant recipi-
ATTITUDES TO XENOTRANSPLANTATION Strongly disagree

\begin{tabular}{ccccccc}
1 & 2 & 3 & 4 & 5 & \multicolumn{2}{c}{ Strongly agree } \\
849 & 156 & 90 & 254 & 121 & 89 & 7 \\
104 \\
$(51.1 \%)$ & $(9.4 \%)$ & $(5.4 \%)$ & $(15.3 \%)$ & $(7.3 \%)$ & $(5.4 \%)$ & $(6.3 \%)$
\end{tabular}

"I would accept an organ from a species closely related to $(51.1 \%) \quad(9.4 \%)$ $(5.4 \%) \quad(15.3 \%)(7.3 \%)$

$(5.4 \%)$

$(6.3 \%)$

chimpanzee)"

\begin{tabular}{lccccccc} 
“I would accept an organ from & 880 & 126 & 85 & 248 & 110 & 83 & 119 \\
$\begin{array}{l}\text { a species distant to man } \\
\text { (e.g. pig or sheep)" }\end{array}$ & $(533 \%)$ & $(7.6 \%)$ & $(5.1 \%)$ & $(15.0 \%)$ & $(6.7 \%)$ & $(5.0 \%)$ & $(7.2 \%)$ \\
\hline
\end{tabular}

The table shows Likert scale frequency and percentage responses to two questions about attitudes to xenotransplantation.

future in which animals would routinely provide bone marrow, hearts, lungs and kidneys for humans, and estimate that 50,000 pig hearts and 40,000 pig kidneys could be transplanted into humans each year.

While these views may reflect the general attitudes of those involved in transplantation and xenotransplantation research, the views of other health professionals suggest differently.

Our analysis of a study of attitudes towards organ donation of 1,728 acute care nurses in 59 Australian public hospitals shows that the majority of these nurses are opposed to xenotransplants. Using a seven-point Likert scale, nurses were asked to grade their feelings towards the two statements: "I would accept an organ from a species closely related to man (for example, baboon or chimpanzee)", and "I would accept an organ from a species distant to man (for example, pig or sheep)".

Approximately two-thirds $(65.5$ per cent) of nurses disagreed with the use of primates as organ donors, 19.0 per cent agreed, 15.3 per cent were undecided. Their responses to the use of pig or sheep organs were closely similar: 66.0 per cent were opposed, 18.9 per cent agreed, 15.0 per cent were undecided. The strength of disagreement with the use of organs from these species is apparent from the table.

1. Lehrman, S. Nature 376, 8 (1995).

Okada-Takagi, M. \& Williams, T. Bioethics News 12 12-30 (1993)

3. The American Public's Attitudes Toward Organ Donation and Transplantation Conducted for the Partnership for Organ Donation, Boston, USA ( Gallup, 1993).

4. Reemstma, K. Transplantn Proc. 22, 1042-1043 (1990).

6. Dickson, D. Nature 377, 185-186 (1995)

7. Hayssen, V., van Tien hoven, A. \& van Tie hoven, A. Asdell's Patterns of Mammalian Reproduction (Cornstock, Cornell Univ. Press, Ithaca, 1993).

8. Nowak, R. M. Walker's Mammals of the World, 5th edn (Johns Hopkins Press, Baltimore, 1991).

9. Holliday, R. Understanding Ageing (Cambridge Univ. Press, 1995).

10. Krohn, P. L. Proc. R. Soc. B. 157, 128-147 (1962).

11. Daniel, C. W. et al. Proc. natn. Acad. Sci. U.S.A. 61 53-60 (1968).

12. Daniel, C. W. \& Young, L. J. T. Exp/ Cell Res. 65, 27-32 (1971). ents $^{2}$, potential transplant recipients (I. F. C. McKenzie, personal communication) and the general community ${ }^{3}$.

The current huge expenditure of money and time on xenotransplantation research will be of little value if people are unwilling to accept animal organs. Reemstma ${ }^{4}$ suggests that when biological barriers to xenotransplantation are overcome, the ethical problems will recede in proportion to the degree of success achieved. However, even if immunological barriers can be overcome, and fears about risks of transmitting donor viral infections allayed, the social unacceptability of clinical xenotransplantation may still prevent it from resolving the present worldwide shortage of organ donors.

Paula J. Mohacsi

Charles E. Blumer

Susan Quine

\section{John F. Thompson}

Department of Public Health

and Community Medicine,

University of Sydney, NSW 2006 ,

Australia

SIR - Your News story about our work with transgenic pigs ${ }^{6}$ raises the important question of timing of initial human studies: what primate data would justify a clinical trial? Some people say that 30-day survival would be sufficient to justify using xenografts as a 'bridge' to transplantation. Others would insist on extensive prolonged survival studies. Clearly, reasonable survival targets must be established somewhere between these two extremes.

Because of the rapid advances in longterm concordant xenograft survival, there is a realistic possibility that our studies on long-term immunosuppressive strategies could, over the next 12 months, deliver such targets. It is therefore appropriate that plans for a clinical programme dealing with such issues as disease control, ethical considerations and regulatory affairs should be initiated as soon as possible. The final decision on when to commence clinical trials will inevitably be based on the experimental data.

\section{David White}

University of Cambridge.

Department of Surgery,

18 Trumpington Road,

Cambridge CB2 $2 A H$, UK

SIR - With the increasing demand for transplant donors, research continues on the possibility that animal organs could be used. This research often centres on pigs (see, for example, ref. 6), because it is believed that their size and general physiology matches that of humans. What never seems to be discussed is the fact that pigs have quite short life spans. Indeed, amongst mammalian species of comparable size, pigs seem to have the shortest life $\operatorname{span}^{7.8}$. This is about 20 years for wild pigs and significantly shorter for domestic animals, which have been selected for particular physical traits. Thus much research on ways and means of overcoming the recipients' rejection mechanisms might be completely foiled by the fairly rapid ageing of the transplanted heart. This would be particularly serious for the most deserving recipients, namely those who are not too old.

This presupposes, of course, that the ageing of the pig heart is intrinsic to its cells and tissues, and is not determined by some extrinsic organism-based mechanism. There is much evidence that ageing at the cellular and tissue level is indeed intrinsic ${ }^{9}$. This includes transplant experiments. For example, it was shown many years ago that mouse skin transplanted to isogeneic recipients became senescent irrespective of the age of the recipient ${ }^{10}$. Similar results were obtained with the transplantation of rat mammary tissue $e^{11,12}$.

Robin Holliday

CSIRO Division

of Biomolecular Engineering,

PO Box 184,

North Ryde NSW 2113,

Sydney, Australia

\section{Bee versus hornet}

SIR - Masato Ono et al. say (Nature 377, 334-336; 1995) that the European honeybee introduced into Japan cannot defend itself against the Japanese giant hornet. Beekeepers in Japan should therefore perhaps consider installing at the entrance to their hives a device similar to the 'queen excluder' used by British beekeepers. The marked difference in size between hornet and bee might make this a practical possibility, not only for the protection of Apis mellifera but also for that of $A$. cerana japonica.

\section{H. Heyworth}

20 Bournside Road,

Cheltenham,

Gloucestershire GL51 5AH, UK 